\title{
Association of Lymphocyte Subsets in Advanced Non-Small Cell Lung Cancer Patients with the Efficacy and Prognosis of Immune Checkpoint Inhibitor Therapy: A Retrospective Study
}

\author{
Yi Yan \\ The first Clinical Medical College of Shanxi Medical University \\ Junmei Jia ( $\sim$ JunmeiJia@163.com) \\ The first Hospital of Shanxi Medical University
}

\section{Research Article}

Keywords: immune checkpoint inhibitors (ICls), biomarkers, non-small cell lung cancer (NSCLC), peripheral blood lymphocyte subsets

Posted Date: December 29th, 2021

DOI: https://doi.org/10.21203/rs.3.rs-1178007/v1

License: @ (i) This work is licensed under a Creative Commons Attribution 4.0 International License. Read Full License 


\section{Abstract Background}

The adaptation of immune checkpoint inhibitors (ICls) has achieved promising effects in patients with non-small cell lung cancer (NSCLC). However, not all patients with NSCLC benefit from immunotherapy. There is an urgent need to explore some biomarkers to predict the efficacy and survival rate of patients with advanced NSCLC after immunotherapy. The objective of this study is to monitor the changes of peripheral blood lymphocyte subpopulations and analyze their correlation with the efficacy and prognosis of immunotherapy.

\section{Methods}

A total of 153 patients with advanced NSCLC were examined. Peripheral blood lymphocyte subsets including $C D 4^{+} T$ cells, CD $8^{+} T$ cells, $\mathrm{CD} 4^{+} / \mathrm{CD} 8^{+}$ratio, NK cells, and Tregs were collected before any treatment, before immunotherapy, and after 4 cycles of immunotherapy. T-test was used to analyze the influencing factors of lymphocyte subtypes and their changes before and after immunotherapy. Logistic regression was used to analyze the relationship between lymphocyte subtypes and efficacy with ROC curve being plotted. Log-rank test and Cox regression model were used to evaluate the relationship between lymphocyte subtypes and progression-free survival (PFS).

\section{Results}

Gender, age, pathology, distant metastasis, and EGFR mutations all affect the proportion of peripheral blood lymphocyte subpopulations in patients with advanced NSCLC. Compared with baseline, the effective group showed that the proportions of $\mathrm{CD} 4^{+} \mathrm{T}$ cells, $\mathrm{CD} 4^{+} / \mathrm{CD} 8^{+}$ratio, NK cells and Tregs were significantly higher, and the proportions of $\mathrm{CD}^{+} \mathrm{T}$ cells were significantly lower in peripheral blood after 4 cycles of immunotherapy. On the contrary, the ineffective group showed no signs of significant differences. Baseline $\mathrm{CD} 4^{+} \mathrm{T}$ cells, NK cells and Tregs were independent predictors of immunotherapy efficacy and PFS.

\section{Conclusions}

Immune checkpoint inhibitors induce changes in the proportion of peripheral blood lymphocyte subsets in patients with effective immunotherapy. The levels of lymphocyte subsets have a good predictive value for efficacy and prognosis of patients with advanced NSCLC.

\section{Introduction}

Lung cancer is one of the most common malignant tumors and the leading cause of cancer deaths worldwide[1]. Non-small cell lung cancer (NSCLC) accounts for about $80 \%$ of primary lung malignancies. Due to improvements in treatment, two-year relative survival rate of NSCLC increased from 30-36\% between 2010 and 2016[2]. The adaptation of immune checkpoint inhibitors (ICls) has achieved promising efficacy and reformed the remedial scenery and clinical outcome of NSCLC patients[3]. However, not all NSCLC patients benefit from immunotherapy, and even 4 to 29 percent of patients with advanced NSCLC who received monoimmunotherapy experienced hyper-progression[4].

There is an urgent need to explore some biomarkers to predict the efficacy and survival of patients with advanced NSCLC after immunotherapy, and to intervene in their treatment strategies as soon as possible. To date, the prognostic value of programmed cell death ligand 1 (PD-L1) expression for immunotherapy has made significant progress[5]. Other biomarkers, such as tumor mutation burden (TMB) and lung immune prognostic index (LIPI), have however yielded conflicting results[6]. Therefore, the development of a dynamic, noninvasive and convenient approach to monitor the efficacy of ICls is the main focus of current research.

The theory of cancer immunoediting, including immune elimination, homeostasis and escape, states that immunity closely relates to the occurrence and progression of cancer, and is the basis of ICls anti-cancer effects[7]. Lymphocytes are essential components of human immune system. Many studies at present focus on tumor-infiltrating lymphocytes (TILs) in the tumor microenvironment, a heterogeneous population including two distinct pools of effector ( $C D 4^{+} T$ cells, $C D 8^{+} T$ cells, NK cells) and suppressor (Tregs) phenotypes. These lymphocytes have been proved to be related to the efficacy of immunotherapy[8]. However,immunoediting occurs not only locally but also systemically to a large extent. Intense lymphocyte trafficking is noticed in NSCLC patients and the phenotype of immune response at the organizational level is also observed in the blood[9]. Thus, we chose to study peripheral blood lymphocyte subsets rather than local immune status. Though numerous studies have shown that compared with healthy population, lung cancer patients have lower $\mathrm{CD} 4^{+} \mathrm{T}$ cells, $\mathrm{CD}^{+} / \mathrm{CD}^{+}$ratio, NK cell levels, and higher regulatory T cells (Tregs) levels[10, 11], the efficacy and prognostic value of peripheral blood lymphocyte subsets in predicting immunotherapy for advanced NSCLC have not been confirmed. 
Our current work aims to actively analyze the impact of clinicopathological characteristics on the peripheral blood lymphocyte subsets of patients with advanced NSCLC in the real world, dynamically monitor the changes of peripheral blood lymphocyte subtypes before and after immunotherapy, and ultimately determine their correlation with immunotherapy efficacy and prognosis.

\section{Materials \& Methods Study population}

We included patients with stage IIIB or IV NSCLC who were treated with PD-1 inhibitors from September 2019 to July 2021 at the First Hospital of Shanxi Medical University. PD-1 inhibitors are pembrolizumab, nivolumab, camrelizumab and sintilimab. Peripheral blood lymphocyte subsets were collected retrospectively before any treatment, before immunotherapy, and after 4 cycles of immunotherapy. The inclusion criteria were as follows: 1 ) clinical stage IIIB or stage IV NSCLC confirmed pathologically or cytologically; 2) first-line or non-first-line treatment with PD-1 inhibitor alone, chemotherapy combined with PD-1 inhibitor or anti-angiogenesis drugs combined with PD-1 inhibitor; 3) ECOG performance status between 0 and 2; and 4) complete lymphocyte subsets and follow-up data. The exclusion criteria precluded the following patients: 1) who were suffering from other types of malignant tumors; 2) who had acute infection, immunodeficiency and autoimmune disorders; 3) who were receiving systemic corticosteroid treatment.

All participants gave informed consent. This study was approved by the Ethical Committee of The first Hospital of Shanxi Medical University(Ethics No.K125) .

\section{Data collection and response assessment}

The clinicopathological data collected for analysis included gender, age at diagnosis, smoking history, pathological type, stage, distant metastasis at first treatment, treatment regimen, and number of treatment lines.

The collected laboratory data included Epidermal growth factor receptor (EGFR) gene mutation, PD-L1 expression, peripheral blood lymphocytes ratio $\left(\mathrm{CD} 4^{+} \mathrm{T}\right.$ cells, $\mathrm{CD} 8^{+} \mathrm{T}$ cells, $\mathrm{CD} 4^{+} / \mathrm{CD} 8^{+}$ratio, NK cells, Tregs) before any treatment, before immunotherapy, and after 4 cycles of immunotherapy. In patients receiving first-line immunotherapy, the ratio of peripheral blood lymphocytes before any treatment and before immunotherapy was the same.

Clinical efficacy of immunotherapy was evaluated based on computed tomography (CT) or magnetic resonance imaging (MRI). The short-term clinical efficacy according to the solid tumor response evaluation criteria (RECIST) included complete response (CR), partial response (PR), stable disease (SD), and disease progression (PD). Patients evaluated as CR, PR, and SD were classified as the effective group, and those evaluated as PD were classified as the ineffective group. The long-term efficacy was evaluated upon the progression-free survival (PFS). PFS time was recorded from the date of first immunotherapy to the date of progression according to RECIST (RECIST-PFS).

\section{Blood collection and flow cytometry}

Lymphocyte subsets (CD4 ${ }^{+} \mathrm{T}$ cells, $\mathrm{CD} 8^{+} \mathrm{T}$ cells, $\mathrm{CD} 4^{+} / \mathrm{CD} 8^{+}$ratio, NK cells, Tregs) were detected in peripheral blood with BD FACSCalibur flow cytometer and flow antibody (both purchased from BD, USA). The method is described as follows: draw $5 \mathrm{ml}$ of whole blood from peripheral vein of fasting patients early in the morning, anti-coagulate with EDTA, add 5 $\mathrm{ll}$ of CD4FITC/CD8PE/CD3PerCP antibodies into the flow tube, add $20 \mu \mathrm{l}$ of EDTA anticoagulated blood at the same time, mix well by vortex shaking, incubate for 15 minutes at room temperature and avoid light, add 10-fold diluted no-wash hemolysin $450 \mu$ l, incubate at room temperature and avoid light for 15 minutes. After the samples were fully hemolyzed, detect cell subpopulation ratio by flow cytometry. The data then was analyzed by MULTISET software.

\section{Statistical analysis}

Quantitative data was expressed as mean \pm standard deviation 0. T-test was adopted for comparison between groups, and paired t-tests for comparison before and after treatment. Qualitative data was expressed as the number of cases (\%), and test was also used for comparison between groups. In prognostic analysis, we used the median proportion of lymphocyte subsets as the threshold to define low and high levels. Prognostic multifactorial analysis was performed with logistic regression. The ROC curve was used to analyze the predictive value of $T$ lymphocyte subsets for the efficacy of immunotherapy in patients with NSCLC. Kaplan-Meier curve was drawn, and the Log Rank test was carried out to compare PFS differences between different groups. Cox proportional hazard regression model was employed to analyze the risk of poor prognosis among different groups after other variables were calibrated. All statistical analyses were fulfilled with the support of SPSS software version 22.0. $P$ value less than 0.05 was considered statistically significant.

\section{Results}




\section{Patient characteristics}

Records of 153 patients in total were included in this study. The clinical and pathological characteristics are reported in Table 1. EGFR gene mutations were detected by next-generation sequencing (NGS) in 129 participants, of which 56 participants were EGFR gene sensitive mutation positive. EGFR gene mutation participants received ICls after EGFR tyrosine kinase inhibitor (EGFR-TKI) treatment. Immunohistochemistry was used to test the protein expressions of PD-L1 in 125 participants, of which 43 had TPS $\geq 50 \%$.

Table 1

Clinical and pathological characteristics

\begin{tabular}{|c|c|c|c|}
\hline Characterstics & & $\mathbf{N}$ & $\%$ \\
\hline \multirow[t]{2}{*}{ Gender } & Male & 97 & 63.4 \\
\hline & Female & 56 & 36.6 \\
\hline \multirow[t]{2}{*}{ Age } & $<65$ & 92 & 60.1 \\
\hline & $\geq 65$ & 61 & 39.9 \\
\hline \multirow[t]{2}{*}{ Smoker } & No & 48 & 31.4 \\
\hline & Yes & 105 & 68.6 \\
\hline \multirow[t]{2}{*}{ Histology } & Adenocarcinoma & 79 & 51.6 \\
\hline & Squamous cell carcinoma & 74 & 48.4 \\
\hline \multirow[t]{2}{*}{ Distant metastasis } & No & 101 & 66.0 \\
\hline & Yes & 52 & 34.0 \\
\hline \multirow[t]{2}{*}{ EGFR mutation } & No & 73 & 56.6 \\
\hline & Yes & 56 & 43.4 \\
\hline \multirow[t]{2}{*}{ PD-L1expression } & $<50 \%$ & 82 & 65.6 \\
\hline & $\geq 50 \%$ & 43 & 34.4 \\
\hline \multirow[t]{2}{*}{ Treatment line } & First line & 102 & 66.7 \\
\hline & Second line and beyond & 51 & 33.3 \\
\hline \multirow[t]{3}{*}{ Treatment model } & ICls alone & 22 & 14.4 \\
\hline & chemotherapy combined with ICls & 125 & 81.7 \\
\hline & Anti-angiogenesis drugs combined with ICls & 6 & 3.9 \\
\hline
\end{tabular}

\section{Factors influencing lymphocyte subtypes}

We collected lymphocyte subtypes from patients with advanced non-small cell lung cancer before any treatment and analyzed the impact of clinicopathological features on lymphocyte subtypes(Table 2). The proportion of NK cells in males was higher than that in females $(P=0.024)$. The proportion of $C D 4^{+} T$ cells $(P=0.023)$ and $C D 4^{+} / C D 8^{+}$ratio $(P=0.038)$ was lower in patients $\geq 65$ years of age than those $<65$ years of age. Patients with adenocarcinoma had higher $C D 8^{+} T$ cells in peripheral blood than those patients with squamous carcinoma $(P=0.046)$, and stage IV patients with distant metastasis had higher proportion of Tregs $(\mathrm{P}=0.027)$. Patients with EGFR mutations had lower $\mathrm{CD} 8^{+} \mathrm{T}$ cells proportion $(\mathrm{P}<0.001)$ and higher $\mathrm{CD} 4^{+} / \mathrm{CD} 8^{+}$ratio $(\mathrm{P}=0.020)$. No effect of smoking and $\mathrm{PD}-\mathrm{L} 1$ expression on baseline lymphocyte subtypes was found. 
Table 2

The impact of clinicopathological characteristics on lymphocyte subtypes

\begin{tabular}{|c|c|c|c|c|c|c|c|c|c|c|}
\hline & $\mathrm{CD}^{+}$ & $P$ & $\mathrm{CD}^{+}$ & $P$ & $\begin{array}{l}\mathrm{CD}^{+} / \\
\mathrm{CD}^{+}\end{array}$ & $P$ & NK & $P$ & Tregs & $P$ \\
\hline Gender & & 0.056 & & 0.058 & & 0.923 & & 0.024 & & 0.172 \\
\hline Male & $34.78 \pm 8.84$ & & $31.46 \pm 9.84$ & & $1.23 \pm 0.53$ & & $21.74 \pm 11.88$ & & $6.37 \pm 1.86$ & \\
\hline Female & $37.76 \pm 9.88$ & & $34.75 \pm 10.99$ & & $1.22 \pm 0.59$ & & $17.34 \pm 10.84$ & & $5.92 \pm 2.08$ & \\
\hline Age & & 0.023 & & 0.061 & & 0.038 & & 0.276 & & 0.494 \\
\hline$<65$ & $37.26 \pm 8.90$ & & $31.34 \pm 9.61$ & & $1.30 \pm 0.54$ & & $19.29 \pm 11.21$ & & $6.29 \pm 1.91$ & \\
\hline$\geq 65$ & $33.78 \pm 9.6$ & & $34.65 \pm 11.19$ & & $1.11 \pm 0.55$ & & $21.39 \pm 12.31$ & & $6.07 \pm 2.01$ & \\
\hline Smoker & & 0.483 & & 0.803 & & 0.820 & & 0.608 & & 0.351 \\
\hline No & $36.66 \pm 10.28$ & & $32.97 \pm 9.61$ & & $1.21 \pm 0.58$ & & $19.41 \pm 11.19$ & & $5.96 \pm 2.41$ & \\
\hline Yes & $35.51 \pm 8.86$ & & $32.52 \pm 10.73$ & & $1.23 \pm 0.54$ & & $20.46 \pm 11.92$ & & $6.32 \pm 1.69$ & \\
\hline Histology & & 0.316 & & 0.046 & & 0.111 & & 0.327 & & 0.887 \\
\hline Adenocarcinoma & $35.14 \pm 8.94$ & & $34.26 \pm 11.33$ & & $1.15 \pm 0.55$ & & $19.23 \pm 11.43$ & & $6.18 \pm 1.94$ & \\
\hline $\begin{array}{l}\text { Squamous cell } \\
\text { carcinoma }\end{array}$ & $36.65 \pm 9.69$ & & $30.95 \pm 8.98$ & & $1.30 \pm 0.55$ & & $21.09 \pm 11.91$ & & $6.23 \pm 1.97$ & \\
\hline $\begin{array}{l}\text { Distant } \\
\text { metastasis }\end{array}$ & & 0.638 & & 0.138 & & 0.306 & & 0.213 & & 0.027 \\
\hline No & $36.13 \pm 8.99$ & & $31.77 \pm 10.09$ & & $1.26 \pm 0.53$ & & $20.97 \pm 12.34$ & & $5.96 \pm 1.91$ & \\
\hline Yes & $35.36 \pm 9.98$ & & $34.40 \pm 10.76$ & & $1.16 \pm 0.59$ & & $18.49 \pm 10.13$ & & $6.69 \pm 1.94$ & \\
\hline EGFR mutation & & 0.824 & & $<0.001$ & & 0.020 & & 0.085 & & 0.673 \\
\hline No & $35.71 \pm 8.57$ & & $35.67 \pm 10.13$ & & $1.11 \pm 0.43$ & & $18.40 \pm 9.96$ & & $6.08 \pm 1.96$ & \\
\hline Yes & $35.35 \pm 9.83$ & & $28.97 \pm 9.47$ & & $1.34 \pm 0.65$ & & $22.06 \pm 13.09$ & & $6.23 \pm 1.95$ & \\
\hline $\begin{array}{l}\text { PD-L1 } \\
\text { expression }\end{array}$ & & 0.861 & & 0.894 & & 0.824 & & 0.580 & & 0.339 \\
\hline$<50 \%$ & $35.46 \pm 9.85$ & & $32.98 \pm 10.46$ & & $1.18 \pm 0.57$ & & $20.02 \pm 11.86$ & & $6.01 \pm 1.66$ & \\
\hline$\geq 50 \%$ & $35.18 \pm 7.74$ & & $33.24 \pm 10.62$ & & $1.21 \pm 0.52$ & & $18.86 \pm 9.58$ & & $6.40 \pm 2.37$ & \\
\hline
\end{tabular}

\section{Changes in lymphocyte subtypes in different therapeutic groups}

After 4 cycles of treatment, out of 153 patients included for this study, 117 patients were classified into the effective group (CR 0, PR 48, SD 69 ) and 36 patients were classified into the ineffective group, with a treatment efficiency of $76.4 \%$. The proportions of $C D 4^{+} T$ cells ( $p<0.001$ ), $C D 4^{+} / C D 8^{+}$ratio $(p=0.010)$, NK cells $(p=0.003)$, and Tregs $(p=0.001)$ in peripheral blood were significantly higher than baseline and the proportions of $\mathrm{CD}^{+} \mathrm{T}$ cells were significantly lower than baseline for the effective group, as shown in Table 3 . No significant differences were found regarding the proportion of $C D 4^{+} T$ cells $(p=0.486), C D 8^{+} T$ cells $(p=0.425), C D 4^{+} / C D 8^{+}$ratio $(p=0.442), N K$ cells $(p=0.346)$, or Tregs $(p=0.394)$ in the peripheral blood of patients compared with baseline for the ineffective group. 
Table 3

Changes in the ratio of lymphocyte subpopulations before and after treatment in the immunotherapy effective and ineffective groups

\begin{tabular}{|c|c|c|c|c|c|c|}
\hline & \multicolumn{3}{|l|}{ Effective group } & \multicolumn{3}{|l|}{ Ineffective group } \\
\hline & Before immunotherapy & After immunotherapy & $P$ & Before immunotherapy & After immunotherapy & $P$ \\
\hline $\mathrm{CD}^{+}$ & $35.78 \pm 8.86$ & $42.09 \pm 9.46$ & $<0.001$ & $31.27 \pm 10.79$ & $30.41 \pm 8.12$ & 0.486 \\
\hline $\mathrm{CD}^{+}$ & $32.51 \pm 10.51$ & $23.63 \pm 7.72$ & $<0.001$ & $35.69 \pm 11.93$ & $36.44 \pm 10.9$ & 0.425 \\
\hline $\mathrm{CD}^{+} / \mathrm{CD}^{+}$ & $1.47 \pm 2.48$ & $2.10 \pm 1.29$ & 0.010 & $1.00 \pm 0.48$ & $0.95 \pm 0.53$ & 0.442 \\
\hline NK & $21.28 \pm 10.49$ & $23.78 \pm 9.05$ & 0.003 & $17.30 \pm 9.88$ & $18.75 \pm 12.01$ & 0.346 \\
\hline Tregs & $6.77 \pm 1.81$ & $7.61 \pm 2.38$ & 0.001 & $5.64 \pm 1.82$ & $5.93 \pm 1.98$ & 0.394 \\
\hline
\end{tabular}

Correlation between baseline lymphocyte subsets and immunotherapy efficacy

A total of 125 patients with complete data were evaluated after 4 cycles of immunotherapy, with 93 in the effective group (CR 0, PR 39, SD 54) and 32 in the ineffective group. Univariate analysis showed that the differences $(P<0.05)$ were statistically significant in PD-L1 expression, $\mathrm{CD}^{+} \mathrm{T}$ cells, NK cells, and Tregs between the two groups $(\mathrm{P}<0.05)$. The proportion of PD-L1 expression $\geq 50 \%$ was high in the effective group of immunotherapy, and the proportion of PD-L1 expression $<50 \%$ was high in the ineffective group. The proportion of baseline CD $4^{+} \mathrm{T}$ cells and Tregs cells was higher in the effective group than that in the ineffective group. we putted these parameters into logistic regression showed that PD-L1 (OR: $0.315,95 \% \mathrm{Cl}: 0.102-0.975, \mathrm{P}=0.045), \mathrm{CD} 4^{+} \mathrm{T}$ cells (OR: $\left.0.903,95 \% \mathrm{Cl}: 0.853-0.957, \mathrm{P}=0.001\right)$, NK cells (OR: $0.913,95 \% \mathrm{Cl}$ : 0.860-0.969, $\mathrm{P}=0.003$ ), and Tregs (OR: $0.645,95 \% \mathrm{Cl}: 0.471-0.883, \mathrm{p}=0.006$ ) were independent predictors of immunotherapy efficacy .

In addition, our ROC working curves demonstrated that the AUC areas of baseline CD $4^{+} \mathrm{T}$ cells, NK cells, and Tregs predicted the efficacy of immunotherapy in NSCLC patients was $0.690,0.634$, and 0.722 respectively, as shown in Figure 1. Corresponding parameter cut-off values for maximum AUC areas were calculated from the maximum Youden index, with a cut-off value of 33.450 for $\mathrm{CD} 4^{+} \mathrm{T}$ cells (sensitivity $=0.656$, specificity=0.719), 12.950 for NK cells (sensitivity=0.817, specificity=0.469), and 4.850 for Tregs (sensitivity $=0.722$, specificity=0.531)(figure 1).

\section{Correlation between baseline lymphocyte subsets and PFS}

Among 125 patients with NSCLC, the median PFS was 9 months (95\% Cl: 7.65-10.35). Univariate analysis showed that females (8.50, $95 \% \mathrm{Cl}$ : 6.71-13.29) had longer PFS than males (8.50, 95\% Cl: 7.02-9.98), patients with PD-L1 expression $\geq 50 \%$ (9.00, 95\% Cl: 7.00-13.01) had longer PFS than those with PD-L1 expression $<50 \%$ (7.00, 95\% Cl: 6.68-10.32), the group with high CD4 ${ }^{+}$T cells ratio (10.0, 95\% Cl: 8.48-11.52) had longer PFS than the group with low $\mathrm{CD}^{+} \mathrm{T}$ cells ratio $(7.50,95 \% \mathrm{Cl}: 6.41-8.60)$, and the group with high NK cells ratio (10.0, $95 \% \mathrm{Cl}$ : $8.82-$ 11.18) had longer PFS than the group with low NK cells ratio $\left(7.50,95 \%\right.$ Cl: 6.08-8.92). Age, smoking, pathology, distant metastasis, $C D 8^{+} T$ cells, and Tregs were not associated with PFS(Table 4). We put gender, PD-L1 expression, CD4 ${ }^{+} \mathrm{T}$ cell, NK cells into a multivariate Cox regression model for analysis. Results revealed that PD-L1 expression (HR: $0.428,95 \% \mathrm{Cl}: 0.245-0.748, \mathrm{P}=0.003), \mathrm{CD}^{+} \mathrm{T}$ cells (HR: $0.454,95 \%$ Cl: $0.271-0.760, P=0.003$ ), and NK cells (HR: $0.491,95 \% \mathrm{Cl}: 0.296-0.813, \mathrm{P}=0.006$ ) were independent predictors of PFS. Kaplan-Meier survival curve analysis of the correlation between proportion of $\mathrm{CD} 4^{+} \mathrm{T}$ cell, NK cells and PFS is shown in Figure 2. 
Table 4

Univariate analysis of the correlation between baseline lymphocyte subsets and PFS in 125 lung cancer participants.

\begin{tabular}{|c|c|c|c|}
\hline & PFS[Month,(95\%Cl)] & Log Rank & $P$ \\
\hline Genger & & 3.862 & 0.049 \\
\hline Male & $8.50(7.02-9.98)$ & & \\
\hline Female & $10.00(6.71-13.29)$ & & \\
\hline Age & & 0.877 & 0.349 \\
\hline$<65$ & $9.00(7.44-10.56)$ & & \\
\hline$\geq 65$ & $8.50(6.78-10.22)$ & & \\
\hline Smoker & & 1.481 & 0.244 \\
\hline No & $9.00(6.60-11.40)$ & & \\
\hline Yes & $8.50(7.53-9.47)$ & & \\
\hline Histology & & 1.004 & 0.316 \\
\hline Adenocarcinoma & $9.50(8.21-10.80)$ & & \\
\hline Squamous cell carcinoma & $7.50(6.15-8.85)$ & & \\
\hline Distant metastasis & & 0.037 & 0.848 \\
\hline No & $10.00(7.43-12.58)$ & & \\
\hline Yes & $8.50(7.58-9.42)$ & & \\
\hline PD-L1 expression & & 5.034 & 0.025 \\
\hline$<50 \%$ & $7.00(6.68-10.32)$ & & \\
\hline$\geq 50 \%$ & $9.00(7.00-13.01)$ & & \\
\hline $\mathrm{CD}^{+} \mathrm{T}$ cells & & 4.093 & 0.043 \\
\hline Low ratio group(<34.30\%) & $7.50(6.41-8.60)$ & & \\
\hline High ratio group( $\geq 34.30 \%)$ & $10.00(8.48-11.52)$ & & \\
\hline $\mathrm{CD}^{+} \mathrm{T}$ cells & & 1.363 & 0.243 \\
\hline Low ratio group(<31.80\%) & $10.00(7.59-12.43)$ & & \\
\hline High ratio group( $\geq 31.80 \%)$ & $8.50(7.08-9.92)$ & & \\
\hline $\mathrm{CD}^{+} / \mathrm{CD}^{+}$ratio & & 4.126 & 0.042 \\
\hline Low ratio group $(<1.07)$ & $8.00(7.00-9.00)$ & & \\
\hline High ratio group $(\geq 1.07)$ & $12.00(9.63-14.37)$ & & \\
\hline NKcells & & 4.212 & 0.040 \\
\hline Low ratio group(<18.90\%) & $7.50(6.08-8.92)$ & & \\
\hline High ratio group $(\geq 18.90 \%)$ & $10.00(8.82-11.18)$ & & \\
\hline Tregs & & 2.783 & 0.095 \\
\hline Low ratio group $(<6.10 \%)$ & $7.50(6.63-8.37)$ & & \\
\hline High ratio group( $\geq 6.10 \%)$ & $10.00(8.35-11.65)$ & & \\
\hline
\end{tabular}


Although immunotherapy has achieved impressive results in the management of advanced NSCLC, reliable biomarkers of efficacy are still limited. Our current work focused on changes in the composition of peripheral blood lymphocyte subsets before and after immunotherapy to assess their potential role in predicting the efficacy and survival for patients with NSCLC. The results showed that compared with baseline, the proportion of $\mathrm{CD} 4^{+} \mathrm{T}$ cells, $\mathrm{CD} 4^{+} / \mathrm{CD}^{+}$ratio, NK cells and Tregs in peripheral blood of the effective group was significantly higher and the proportion of $\mathrm{CD}^{+} \mathrm{T}$ cells was significantly lower. In contrast, there was no statistically significant difference in the changes of such biomarkers for the ineffective group. Higher proportions of baseline CD $4^{+} \mathrm{T}$ cells and NK cells were associated with effective immunotherapy and longer PFS, and higher proportions of baseline Tregs were associated with effective immunotherapy. The ROC curves further confirmed the predictive role of $\mathrm{CD} 4^{+} \mathrm{T}$ cells, NK cells, and Tregs on the efficacy of immunotherapy. Moreover, we analyzed the factors that affect lymphocyte subtypes, with the goal of determining the ratio of peripheral blood lymphocyte subpopulations by clinicopathological characteristics, in order to screen the population that may benefit from immunotherapy. Results showed that NK cells were higher in males, proportion of $\mathrm{CD}^{+} \mathrm{T}$ cells and $\mathrm{CD} 4^{+} / \mathrm{CD} 8^{+}$ratio was lower in patients $\geq 65$ years of age, $\mathrm{CD} 8^{+} \mathrm{T}$ cells were higher in peripheral blood for patients with adenocarcinoma, percentage of Tregs was higher in stage IV patients with distant metastasis, percentage of CD ${ }^{+} \mathrm{T}_{\text {cells }}$ was lower and $\mathrm{CD}^{+} / \mathrm{CD}^{+}$ratio was higher in patients with EGFR mutations. This is consistent with the findings of Mazzaschi et al[12, 13, 14].

As a core participant of antitumor immunity, $C D 4^{+} \mathrm{T}$ cells help promote priming, migratory potential, and killing activity of cytotoxic $\mathrm{T}$ lymphocytes (CTLs)[15]. Our study showed that the CD4 ${ }^{+} \mathrm{T}$ cells proportion of patients in the effective immunotherapy group increased compared with the baseline, while the change of $\mathrm{CD} 4^{+} \mathrm{T}$ cells in the ineffective group was not significant statistically. This is because a durable antitumor response requires continuous recruitment of antitumor $T$ cells through peripheral blood[16]. Previous studies have reached similar conclusions as ours. Kagamu et al. demonstrated that CD $4^{+} \mathrm{T}$ cells play a key role in the blockade efficacy of PD-L1/PD-1 and found that the relative percentage of $\mathrm{CD}^{+}$memory $\mathrm{T}$ cells in peripheral blood before the start of immunotherapy has a strong predictive power for clinical benefit[17]. Another study also discovered high levels of CD $4^{+} \mathrm{T}$ cells were associated with longer overall survival (OS) and PFS in advanced NSCLC patients treated with nivolumab[18].

In addition, we found that the proportion of $\mathrm{CD}^{+} \mathrm{T}$ cells in the immunotherapy effective group decreased from the baseline, which is consistent with the findings of Minglei et al[19]. Accordingly, the CD $4^{+} / \mathrm{CD} 8^{+}$ratio was higher than at baseline. The CD4+/CD8+ ratio is a marker of cell-mediated immunity in cancer patients, and its reduction is related to a low immunological function[20]. This proved that the immunosuppression status of patients in the effective immunotherapy group had been improved.

Current studies on CD8 ${ }^{+} \mathrm{T}$ cells in peripheral blood mainly focus on PD- $1^{+} \mathrm{CD} 8^{+} \mathrm{T}$ cells. Several studies have shown that NSCLC patients with high baseline PD $-1^{+} \mathrm{CD} 8^{+} \mathrm{T}$ cell levels achieve longer OS after receiving nivolumab treatment[18, 21]. After ICI treatment, approximately $70 \%$ of the patients had increased Ki67 expression, and their PD $-1^{+} \mathrm{CD} 8^{+} \mathrm{T}$ cells showed active proliferation. This group of patients was more likely to respond to $\mathrm{ICl}$ and obtain longer PFS[22]. However, the predictive value of peripheral blood $\mathrm{CD}^{+} \mathrm{T}$ cell ratio in immunotherapy has not yet been validated by studies including ours, and further studies on absolute number of $\mathrm{CD} 8^{+} \mathrm{T}$ cells, CD $8^{+} \mathrm{T}$ cells subtypes, and infiltrated CD $8^{+} \mathrm{T}$ cells in tissues deem necessary to follow up.

Toshiko's research in earlier years confirmed that the blockade of PD-L1 leads to the activation of NK cells and enhances the direct antitumor function of NK cells[23]. Myeong et al. also indicated that NK cells activity can be used as a biomarker to predict the response to immunotherapy of NSCLC[24]. Our research corroborated it in that the NK cells ratio for patients in the effective immunotherapy group increased compared to the baseline and higher baseline NK cells ratio is correlated with better efficacy and longer PFS. This is consistent with the research done by Giulia and Peng et al[25, 12]. In summary, the positive role of NK cells for tumor immune monitoring has been confirmed with more and more studies. Nowadays, medicines that modulate the proliferative activity and function of NK cells have been developed in purpose of producing synergistic antitumor efficacy on ICls through combination therapies[26, 27]. Our results will further advance this field of research by increasing baseline NK cell levels in patients with advanced non-small cell lung cancer in order to benefit a larger population from immunotherapy.

Tregs play a crucial immunosuppressive role in patients with cancer. Our research showed that Tregs of patients in clinical benefit group increased compared to the baseline. This may be due to the Treg-NK interaction. Tregs selectively express membrane-bound transforming growth factor- $\beta$, down-regulate the expression of NKG2D on NK cells in vitro and in vivo and inhibit NK cells effector functions as a means of achieving immune homeostasis in organisms[28].Giulia et al. also observed that following PD-1 blockade, the rise in NK cells in clinical benefit group was accompanied by a significant increase in the number and proliferation of Tregs[12]. Current study also showed that a high Tregs ratio at baseline predicts a good immunotherapeutic response, in agreement with the findings of Jose et al. They observed an inverse correlation between the number of tumor Tregs and the number of peripheral Tregs in the mouse tumor model[29]. This means that ICls treatment improves local immune microenvironment in the tumor. However, this study did not find a correlation between Tregs and long-term survival. Analyzing the role of circulating Treg subsets, Athanasios et al. manifested for the first time that at baseline, high levels of naive and 
effector Tregs were associated with longer overall survival, while high frequency of terminal effector Tregs was associated with longer PFS and 0 [30]. Jinyan et al. provided evidence that FOXA1+ Treg subsets promote tumor growth and incur poor response to lung cancer treatment[31]. Our next study will focus on the correlation between peripheral blood Treg subsets and long-term survival of immunotherapy so as to provide novel and reliable targets for inhibiting Tregs.

We must acknowledge the limitations in our study. First, our work did not obtain the absolute count of lymphocyte subsets. It would be more valuable in future studies to prospectively collect samples for analyzing the percentage and absolute count of lymphocyte subpopulations. Furthermore, ICls and treatment combinations from different pharmaceutical companies added confounding factors into the analysis of the study. Finally, considering the benefit to OS is the main goal of immunotherapy for lung cancer patients, we need to extend the observation time and treatment cycles and monitor lymphocyte subtype changes longitudinally to explore their correlation with oS in continuing research.

\section{Conclusions}

In summary, our results indicate that immune checkpoint inhibitors induce changes in the proportion of peripheral blood lymphocyte subsets in patients with effective immunotherapy, high level of $\mathrm{CD} 4^{+} \mathrm{T}$ cells, NK cells and Tregs can predict better efficacy in patients with NSCLC, and high level of $\mathrm{CD}^{+} \mathrm{T}$ cells and NK cells are associated with longer PFS. Therefore, peripheral blood lymphocyte subsets may serve as efficacy and prognosis biomarkers for NSCLC patients.

\section{Abbreviations}

NSCLC: Non-small cell lung cancer,ICls:Immune checkpoint inhibitor,PFS:progression-free survival,Tregs $\$ regulatory T cells, PD-L1:programmed cell death ligand 1, TMB:tumor mutation burden,LIPI:lung immune prognostic index, TILs:tumor-infiltrating lymphocytes,EGFR:Epidermal growth factor receptor,CT:computed tomography,MRI:magnetic resonance imaging,CR:complete response, PR:partial response, SD:stable disease,PD:disease progression,RECIST: the solid tumor response evaluation criteria,NGS:next-generation sequencing,EGFR-TKI:EGFR tyrosine kinase inhibitor,CTLs:cytotoxic T lymphocytes

\section{Declarations}

\section{Ethics approval and consent to participate}

As the retrospective nature of our study,we contacted patients by telephone to obtain informed consent from them and made telephone recordings. The Ethical Committee of first Hospital of Shanxi Medical University reviewed the telephone recordings and approved our study(Ethics No.K125).All methods were performed in accordance with the relevant guidelines and regulations.All participants gave informed consent.

\section{Consent for publication}

Not applicable.

\section{Availability of data and materials}

The datasets used and/or analyzed during the current study are available from the corresponding author upon reasonable request.

\section{Competing interests}

The authors declare that they have no competing interests.

\section{Funding}

Not applicable.

\section{Authors' contributions}

YY and JMJ participated in the research design, YY performed data analysis and charting,YY and JMJ participated in the writing and revision of the manuscript. All authors read and approved the final manuscript.

\section{Acknowledgements}


We thank all the members in Department of Medical Oncology of the first Hospital of Shanxi Medical University for their help and valuable opinion.

\section{References}

1. Sung H, Ferlay J, Siegel RL, Laversanne M, Soerjomataram I, Jemal A, Bray F. Global Cancer Statistics 2020: GLOBOCAN Estimates of Incidence and Mortality Worldwide for 36 Cancers in 185 Countries. CA Cancer J Clin. 2021;71(3):209-249.

2. Siegel RL, Miller KD, Fuchs HE, Jemal A. Cancer Statistics, 2021. CA Cancer J Clin. 2021;71(1):7-33.

3. Johnson DB, Rioth MJ, Horn L. Immune checkpoint inhibitors in NSCLC. Curr Treat Options Oncol. 2014;15(4):658-69.

4. Adashek JJ, Subbiah IM, Matos I, Garralda E, Menta AK, Ganeshan DM, Subbiah V. Hyperprogression and Immunotherapy: Fact, Fiction, or Alternative Fact? Trends Cancer. 2020;6(3):181-191.

5. Aguiar PN Jr, De Mello RA, Hall P, Tadokoro H, Lima Lopes G. PD-L1 expression as a predictive biomarker in advanced non-small-cell lung cancer: updated survival data. Immunotherapy. 2017;9(6):499-506.

6. Proto C, Ferrara R, Signorelli D, Lo Russo G, Galli G, Imbimbo M, Prelaj A, Zilembo N, Ganzinelli M, Pallavicini LM, De Simone I, Colombo MP, Sica A, Torri V, Garassino MC. Choosing wisely first line immunotherapy in non-small cell lung cancer (NSCLC): what to add and what to leave out. Cancer Treat Rev. 2019;75:39-51.

7. Carlisle JW, Steuer CE, Owonikoko TK, Saba NF. An update on the immune landscape in lung and head and neck cancers. CA Cancer J Clin. 2020;70(6):505-517.

8. Barua S, Fang P, Sharma A, Fujimoto J, Wistuba I, Rao AUK, Lin SH. Spatial interaction of tumor cells and regulatory T cells correlates with survival in non-small cell lung cancer. Lung Cancer. 2018;117:73-79.

9. Chen DS, Mellman I. Elements of cancer immunity and the cancer-immune set point. Nature. 2017;541(7637):321-330.

10. Wei Z, Zhang W, Gao F, Wu Y, Zhang G, Liu Z, Jiao S. Impact of Lymphocyte Subsets on Chemotherapy Efficacy and Long-term Survival of Patients with Advanced Non-small-cell Lung Cancer. Zhongguo Yi Xue Ke Xue Yuan Xue Bao. 2017;39(3):371-376.

11. Qiu J, Che G, Liu F, Sha X, Ju S, Ma H, Feng L. The detection and clinical significance of peripheral regulatory CD4+CD25hiCD127low T cells in patients with non-small cell lung cancer. Clin Transl Oncol. 2019;21(10):1343-1347.

12. Mazzaschi G, Facchinetti F, Missale G, Canetti D, Madeddu D, Zecca A, Veneziani M, Gelsomino F, Goldoni M, Buti S, Bordi P, Aversa F, Ardizzoni A, Quaini F, Tiseo M. The circulating pool of functionally competent NK and CD8+ cells predicts the outcome of anti-PD1 treatment in advanced NSCLC. Lung Cancer. 2019;127:153-163.

13. Dai S, Ren P, Ren J, Yang L, Li W. The Relationship between Lymphocyte Subsets and the Prognosis and Genomic Features of Lung Cancer: A Retrospective Study. Int J Med Sci. 2021;18(10):2228-2234.

14. Li YD, Lamano JB, Lamano JB, Quaggin-Smith J, Veliceasa D, Kaur G, Biyashev D, Unruh D, Bloch O. Tumor-induced peripheral immunosuppression promotes brain metastasis in patients with non-small cell lung cancer. Cancer Immunol Immunother. 2019;68(9):1501-1513.

15. Kagamu H, Kitano S, Yamaguchi O, Yoshimura K, Horimoto K, Kitazawa M, Fukui K, Shiono A, Mouri A, Nishihara F, Miura Y, Hashimoto K, Murayama Y, Kaira K, Kobayashi K. CD4+ T-cell Immunity in the Peripheral Blood Correlates with Response to Anti-PD-1 Therapy. Cancer Immunol Res. 2020;8(3):334-344.

16. Spitzer MH, Carmi Y, Reticker-Flynn NE, Kwek SS, Madhireddy D, Martins MM, Gherardini PF, Prestwood TR, Chabon J, Bendall SC, Fong L, Nolan GP, Engleman EG. Systemic Immunity Is Required for Effective Cancer Immunotherapy. Cell. 2017;168(3):487-502.e15.

17. Zuazo M, Arasanz H, Fernández-Hinojal G, García-Granda MJ, Gato M, Bocanegra A, Martínez M, Hernández B, Teijeira L, Morilla I, Lecumberri MJ, Fernández de Lascoiti A, Vera R, Kochan G, Escors D. Functional systemic CD4 immunity is required for clinical responses to PD-L1/PD-1 blockade therapy. EMBO Mol Med. 2019;11(7):e10293.

18. Ottonello S, Genova C, Cossu I, Fontana V, Rijavec E, Rossi G, Biello F, Dal Bello MG, Tagliamento M, Alama A, Coco S, Boccardo S, Vanni I, Ferlazzo G, Moretta L, Grossi F, Mingari MC, Carrega P, Pietra G. Association Between Response to Nivolumab Treatment and Peripheral Blood Lymphocyte Subsets in Patients With Non-small Cell Lung Cancer. Front Immunol. 2020 Feb;11:125.

19. Zhuo M, Chen H, Zhang T, Yang X, Zhong J, Wang Y, An T, Wu M, Wang Z, Huang J, Zhao J. The potential predictive value of circulating immune cell ratio and tumor marker in atezolizumab treated advanced non-small cell lung cancer patients. Cancer Biomark. 2018;22(3):467-476.

20. Xu J, Jiang L, Cao H, Jia Y, Wu S, Jiang C, et al. Predictive value of CD4+/ CD8+ ratio in patients with breast cancer receiving recombinant human thrombopoietin. J Interferon Cytokine Res. 2018;38(5):213-220.

21. Kim CG, Hong MH, Kim KH, Seo IH, Ahn BC, Pyo KH, Synn CB, Yoon HI, Shim HS, Lee YI, Choi SJ, Lee YJ, Kim EJ, Kim Y, Kwak JE, Jung J, Park SH, Paik S, Shin EC, Kim HR. Dynamic changes in circulating PD-1+CD8+ T lymphocytes for predicting treatment response to PD-1

Page $10 / 12$ 
blockade in patients with non-small-cell lung cancer. Eur J Cancer. 2021;143:113-126.

22. Kamphorst AO, Pillai RN, Yang S, Nasti TH, Akondy RS, Wieland A, Sica GL, Yu K, Koenig L, Patel NT, Behera M, Wu H, McCausland M, Chen Z, Zhang C, Khuri FR, Owonikoko TK, Ahmed R, Ramalingam SS. Proliferation of PD-1+ CD8 T cells in peripheral blood after PD-1-targeted therapy in lung cancer patients. Proc Natl Acad Sci U S A. $2017 ; 114(19): 4993-4998$.

23. Kamata T, Suzuki A, Mise N, Ihara F, Takami M, Makita Y, Horinaka A, Harada K, Kunii N, Yoshida S, Yoshino I, Nakayama T, Motohashi S. Blockade of programmed death-1/programmed death ligand pathway enhances the antitumor immunity of human invariant natural killer T cells. Cancer Immunol Immunother. 2016;65(12):1477-1489.

24. Choi MG, Kim YJ, Lee JC, Rho JK, Choi CM. Efficacy of natural killer cell activity as a biomarker for predicting immunotherapy response in non-small cell lung cancer. Thorac Cancer. 2020;11(11):3337-3345.

25. Li P, Qin P, Fu X, Zhang G, Yan X, Zhang M, Zhang X, Yang J, Wang H, Ma Z. Associations between peripheral blood lymphocyte subsets and clinical outcomes in patients with lung cancer treated with immune checkpoint inhibitor. Ann Palliat Med. 2021;10(3):3039-3049.

26. Zingoni A, Fionda C, Borrelli C, Cippitelli M, Santoni A, Soriani A. Natural Killer Cell Response to Chemotherapy-Stressed Cancer Cells: Role in Tumor Immunosurveillance. Front Immunol. 2017;8:1194.

27. Yang Y, Li L, Jiang Z, Wang B, Pan Z. Anlotinib optimizes anti-tumor innate immunity to potentiate the therapeutic effect of PD-1 blockade in lung cancer. Cancer Immunol Immunother. 2020;69(12):2523-2532.

28. Ghiringhelli F, Ménard C, Martin F, Zitvogel L. The role of regulatory T cells in the control of natural killer cells: relevance during tumor progression. Immunol Rev. 2006;214:229-38.

29. Kim HR, Park SM, Seo SU, Jung I, Yoon HI, Gabrilovich DI, Cho BC, Seong SY, Ha SJ, Youn JI. The Ratio of Peripheral Regulatory T Cells to Lox-1+ Polymorphonuclear Myeloid-derived Suppressor Cells Predicts the Early Response to Anti-PD-1 Therapy in Patients with Non-Small Cell Lung Cancer. Am J Respir Crit Care Med. 2019;199(2):243-246.

30. Kotsakis A, Koinis F, Katsarou A, Gioulbasani M, Aggouraki D, Kentepozidis N, Georgoulias V, Vetsika EK. Prognostic value of circulating regulatory T cell subsets in untreated non-small cell lung cancer patients. Sci Rep. 2016;6:39247.

31. Liang J, Tian C, Zeng Y, Yang Q, Liu Y, Liu Y, Wu J, Hu Y, Gu F, Zhang K, Wang Y, Zhang Y, Liu L. FOXA1+ regulatory T cells: A novel T cell subset that suppresses antitumor immunity in lung cancer. Biochem Biophys Res Commun. 2019;514(1):308-315.

\section{Figures}

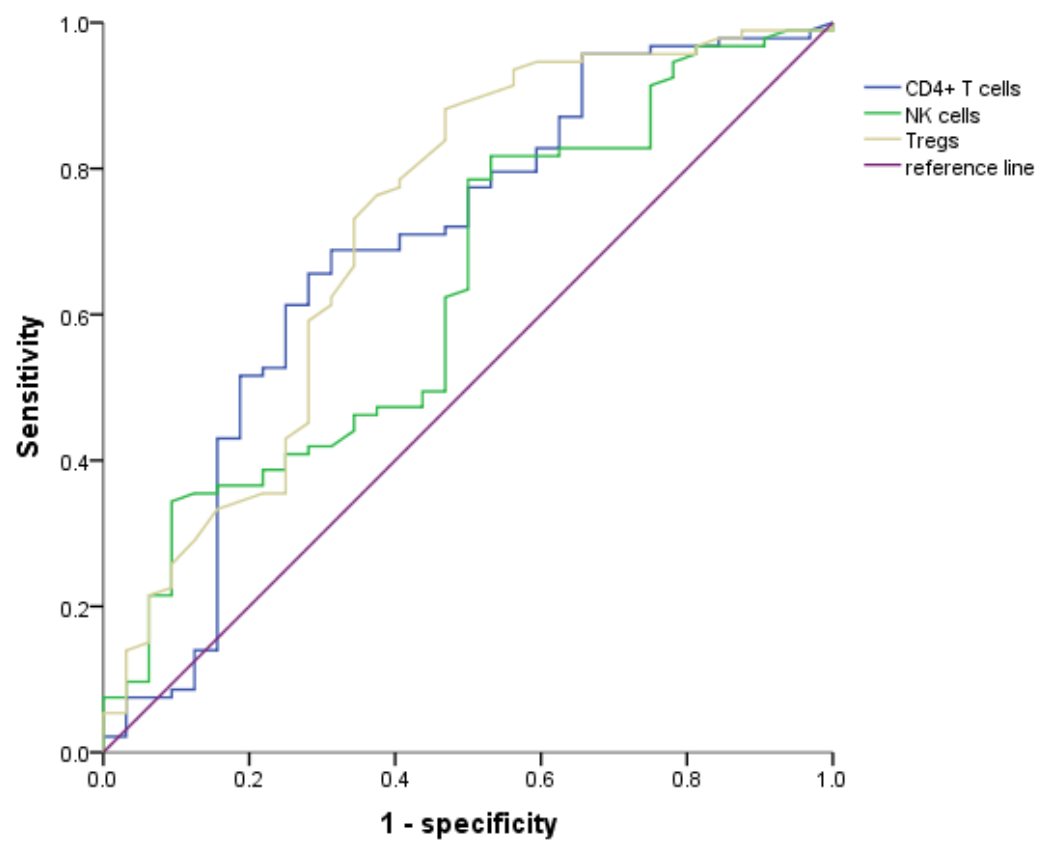

同分産生的對数區段。

\section{Figure 1}

The ROC curve of $\mathrm{CD} 4^{+} \mathrm{T}$ cells, NK cells and Tregs levels before immunotherapy. 
A

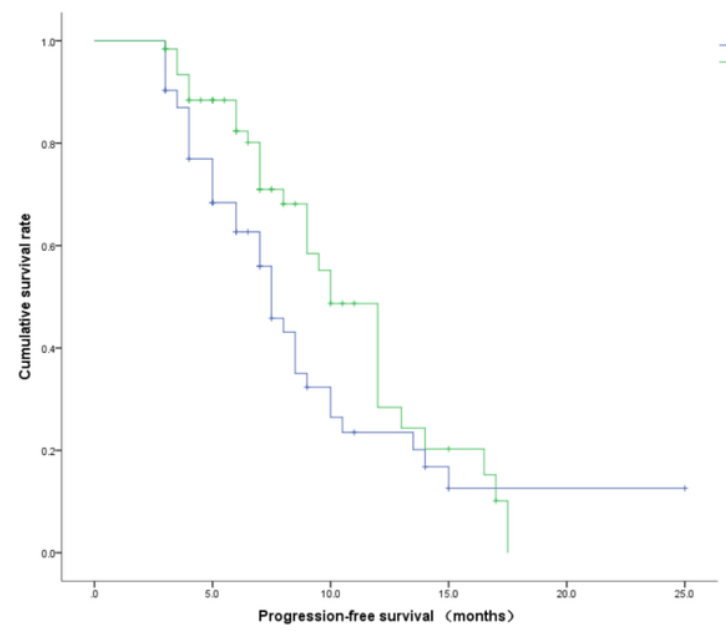

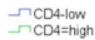

B

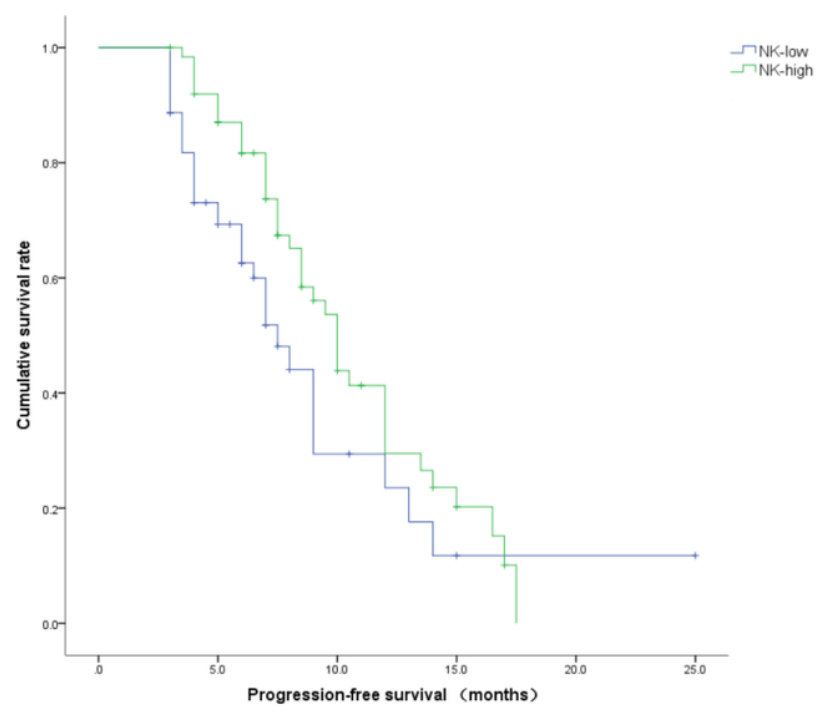

Figure 2

Kaplan-Meier survival curve of the correlation between proportion of CD4+ T cell, NK cells and PFS

A PFS survival curve by $\mathrm{CD} 4^{+} \mathrm{T}$ cells

B PFS survival curve by NK cells 